\title{
The effects of three different type of exercises on aerobic and anaerobic power
}

\author{
Alpaslan Gorucu ${ }^{1}$, Bekır Tokay ${ }^{1}$, Adela Badau² \\ ${ }^{1}$ Faculty of Sport Sciences, Selcuk University, Konya, Turkey \\ ${ }^{2}$ Department of Physical Education, Faculty of Medicine, \\ University of Medicine and Pharmacy of Targu Mures, Romania
}

\begin{abstract}
Purpose:

The study was conducted with the aim of investigating the effects of three different types of exercise: bicycling, plyometric and weight on aerobic and anaerobic power.

Material: $\quad$ Sample size 30 students recreational athletes aged 23,19 years. The athletes were divided into 3 groups of 10 subjects (bicycle, plyometric, weight). The program for 6 weeks included: 3 different exercises planned for 30 minute/3 days/week. Body weight, vertical jump and 20-meter shuttle running tests were measured for each group. Statistical analysis was performed by SPSS21.0: arithmetic averages and standard deviations; the Kruskal-Wallis $\mathrm{H}$ test was used to determine the differences between the groups; the Mann-Whitney $\mathrm{U}$ test was used to determine the group which result in the difference among the groups; Wilcoxon 's t test was used to determine pretest posttest differences within the groups.

Results: $\quad$ As a result of the research, it was determined that the increase in the aerobic power levels of the bicycle and plyometric groups was significant $(p<0.05)$, but the increase in the weight group was not significant $(p>0.05)$.

Conclusions: The different exercises practiced by all three groups significantly increased anaerobic power levels. When the aerobic and anaerobic power values of the three groups in each study were examined, it was found that only the increase of weight and plyometric groups was high level in favor of the weight group in terms of posttest aerobic power.

Keywords: aerobic power, anaerobic power, bicycling, plyometric, weight.
\end{abstract}

\section{Introduction}

Motor activity provides multiple directions for research with a strong social impact, it is in direct relation to the technological development and the new scientific discoveries in related fields which determine the optimization of human motric potential [1]. Exercises not only bring physical fitness to the highest level as well as provide a longer, better quality of life, but also have many positive effects on health [2].

The effort capacity is a characteristic of the individual who performs a motor activity and is appreciated by the duration of the effort, the mechanical work and its opportunity [3]. In the field of adaptation to effort, from a conceptual point of view, the tendency is to replace the notion of homeostasis with homeorhetis, which designates a complex of progressive balancing and rebalancing, materialized in modifications: plastic, functional, biochemical and technical [3].

Scientific research in human motor field contributes to knowledge about how our bodies perform, what is the relationships between components of motor capacity related to the factors of psyhic, social etc. [4]. It is necessary to raise the quality of young people's training. Rather important are modern training methodic,permitting for teachers to use new effective forms and methods of physical education in educational process [5].

Plyometric training is a type of muscle strength exercise that can improve basic physical strength. It has been extensively studied for its ability of improving exercise performance [6]. It is thought that the plyometric exercise [7] which is defined as intense exercises performed with maximal force, that are performed to obtain physical performance changes for sportive activities, comes from word roots meaning plethysm or measure (plio) in

(C) Alpaslan Gorucu, Bekır Tokay, Adela Badau, 2017

doi:10.15561/20755279.2017.0401
Greek. Plyometric exercises are also defined as activities requiring maximal effort, such as high-intensity depth jumps workouts [8].

The basis of the plyometric exercises is stretch shortening cycle which allows the concentric contraction to increase during eccentric motion. Thus, the speed of the eccentric contraction movement is very significant for concentric contractions [9]. Leg pedaling exercises such as bicycling are generally preferred to increase muscle strength and endurance. Numerous studies have been conducted to understand the development of leg muscle function and coordination and the clinical impact of cycling exercise [10].

Isotonic training, that is weight trainings done with weight training machines or free weight, is highly preferred. Contrary to isometric exercises, isotonic exercise provides a constant load during a movement. Routine weight training can cause muscle tone, strength and stamina to increase. It has also been shown to develop tendon and ligament strength [2].

Anaerobic exercises are defined as studies of the highest possible oxygen borrowing capacity of the organism. In order to adequately stimulate the anaerobic energy pathways, it is necessary to apply strongly dynamic loads near the maxima. Oxygen and energy needs are raised to the highest level, aiming to operate the organism under difficult conditions [11]. Aerobic exercises are defined as the ability of the organism to receive, transport and use oxygen [11].

Aerobic exercises have no effect on strength gain (2 or 3 times a week for 20 to 30 minutes, $75 \%$ of the maximal heart rate) but can adversely affect the power increase [9].

Purpose and hypothesis

The study was conducted with the aim of investigating the effects of three different types of exercise: bicycling, plyometric and weight on aerobic and anaerobic power. 
The hypothesis of the study started from the assumption that the implementation of 3 diferent programs bicycling exercise, plyometric exercises and weight training will have different effect on aerobic and anaerobic power on the students recreationa athlets.

\section{Material and Methods}

Participants: A total of 30 male students recreational athletes, age of 21,19 years, who did not practice professional sports, actively fulfilled exercises for 3 days a week for at least 2 hours and were voluntarily participated in the study. The subjects were selected from the athletes who had not experienced any neurological, audiovisual discomfort and serious injuries in the upper and lower limbs during the past six months. At the beginning of the study, the athletes were told about the tests they would be subject to in the scope of the research and a document regarding their voluntariness was signed. The sportsmen were divided into groups considering the homogeneity, and each group was consists from 10 students recreational athletes.

Procedure: The research was carried out between February - May 2016. Exercises increasing quadriceps and hamstring muscle strength were performed for 3 days per week for 6 weeks. In Table 1. we calculated the ages, size and body weight. Size: Measurements of length (Welch Allyn) were made while the athlete was standing in a upright position. On the scale, the caliper sliding on the scale is adjusted to touch the head of the athlete and the length is read with a sensitivity within $1 \mathrm{~mm}$. Body Weight: Body weight measurements were made with a sensitivity within 20-gram bottle (Welch Allyn), with bare feet and shorts only.

\section{Training Procedure}

Bicycling exercise: In the (BE) exercise group, the athletes were subjected to overexercise, corresponding to $75 \%$ of their maximal heart rate for 30 minutes, 3 times a week for 6 weeks by with the BL 909D Starline brand stationary bicycle. The pulse rate of the athletes was calculated by 220 heart rate formula and the pulse interval was found and followed by the polar watch.

Plyometric exercise: Plyometric exercise (PE) was done to the sportsmen, 3 sets of 10 repetitions for the first three weeks, 3 sets of 15 repetitions for the last three weeks. 1 minute breaks between sets and 2 minutes breaks between movements were given. The plyometric exercises that are performed by the athletes during 6 weeks of exercise are: skip jumping, squat jumping, double jumping forward, single jumping forward, side jumping, depth jumping on the boxes, depth jumping performed between the boxes, split jump.

Weight training (WE): the athletes performed three sets of 10 repetitions of exercise movements. Athletes had worked with $80 \%$ of the weight they could maximal in exercises. The weights that the athletes can take up $80 \%$ each week were recalculated and worked. 1 rest between sets, 2 minutes rest between movements were given. The plyometric exercises that were performed by the athletes during the 6-week exercise period were: Leg press, hack squat machine, seated leg curll, leg extensions.

Aerobic Capacity Test - 20 meter shuttle run test $\left(\mathrm{VO}_{2 \max }\right.$ measurement) (Table 2): A shuttle run test was performed to measure the aerobics of the athletes. The athletes were running $20 \mathrm{~m}$. The test was started at a slow running speed $(8 \mathrm{~km} / \mathrm{h})$, the athlete started to run in the first signal and tried to reach the line until the $2^{\text {nd }}$ signal. When it hears the $2^{\text {nd }}$ signal, it goes back to the starting line again. The running speed continued to increase by $0.5 \mathrm{~km} / \mathrm{s}$ every minute. When the athlete heard the signal, $\mathrm{s} /$ he tried to adjust his/her tempo to be at the other end of the track in the second signal. In the beginning, the slow speed gradually increased every 10 seconds. The athlete continued to test if he missed a signal and reached second place. When the athlete misses two signals, the test is ended.

Calculation of Anaerobic Power - High jump test (Table 2) was applied to measure the anaerobic strength of the athletes. Athletes first stood side by side and naturally stood at the edge of the wall. The point closest to the wall is marked with the uppermost point, and then the uppermost spot reached by jumping is determined. The difference between the first point and the point reached after the jump is measured in meters. Sportsmen were asked to jump twice. Based on the vertical jump values of the anaerobic power capacities of the athletes, these data were calculated using the Lewis Formula.

\section{Anaerobic power (kg.m.sn) $P=\sqrt{4}, 9 \times$ Body weight (kg) $x \sqrt{ } D$}

$\mathrm{P}=$ Anaerobic power $(\mathrm{kg}-\mathrm{m} / \mathrm{s})$, vertical jump

$\mathrm{D}=$ Vertical jump distance in meters, 4.9 is a constant coefficient (Günay et al., 2013).

Statistical Analysis: The statistical evaluation of the findings was performed with SPSS 21.0 computer package program, and the arithmetic mean and standard deviations of all parameters were excluded. The Kruskal-Wallis $\mathrm{H}$ test was used to determine group differences, and the Mann-Whitney U test was used to determine the group from which the difference was derived. The KruskalWallis $\mathrm{H}$ test was used to determine the differences between the groups and the Mann-Whitney U test was used to determine the group which result in the difference among the groups because of the low number of total data $(n=30)$. Wilcoxon's t test was used to determine pretest posttest differences within the groups. $\mathrm{P}<0.05$ was considered as significant level.

\section{Results}

30 studetnts recreational athletes participated in the study with the aim of investigating the effect of different types of exercise on aerobic and anaerobic power; Age, height, body weight, anaerobic and aerobic power values are given below in tabular form.

No statistically significant difference was found among age, height and body weight values between groups $(\mathrm{p}>0,05)$.

When the aerobic and anaerobic power values of the 
cycling group were examined, a statistically significant difference was found between pretest and posttest values $(\mathrm{p}<0.05)$ (Table 2).

When the aerobic and anaerobic power values of the plyometric group were examined in the study, a statistically significant difference was found between pretest and posttest values $(\mathrm{p}<0.05)$ (Table 2$)$.

When the anaerobic power values of the weight group were examined in the study, a statistically significant difference was found in pretest and posttest values $(\mathrm{p}<0.05)$ (Table 2) .

When the weight group's aerobic power values were examined, there was no statistically significant difference between pretest and posttest values, although there was a significant increase in favor of posttest ( $p>0.05$ ) (Table 2).

When the aerobic and anaerobic power pretest and posttest values of the groups were examined in the study, no significant difference was found in all other measurements of the groups ( $p>0.05)$, although there was a significant increase in favor of posttest in aerobic power measurements $(\mathrm{p}<0.05)$ (Table 3$)$.

\section{Discussions}

In this study, the effects of exercise programs performed with three different types of exercise groups performed 8 different pliometer bounce drills and four different leg weight exercises done with $80 \%$ of 1 Repetition Maximum (1RM) as well as did 30 minute bicycle exercise with $75 \%$ pulse applied for 3 days a week throughout 6 weeks, over the isokinetic stregth of quadriceps and hamstring muscles were investigated.

In the study, the anaerobic forces of all three groups were measured by the vertical jump applied before and after the exercises and the aerobic power were measured by the $20 \mathrm{~m}$ shuttle running test (Table 2, 3).

The research findings show that the anaerobic and aerobic powers of the bicycle group increased significantly in favor of the post tests, according to pretest and posttest results of force values (Table 2).

The research supports this findings of Martinmäki [12], reporting that the 6-week high intensity interval cycling training increases the jumping strength and according to the result of this research, the cycling

Table 1. The statistical analysis of the age (years), size $(\mathrm{cm})$ and body weight $(\mathrm{kg})$ of the groups

\begin{tabular}{llll}
\hline Groups & Age $(x \pm S D)$ & Size $(x \pm S D)$ & Body Weight $(x \pm S D)$ \\
\hline Bicycle $(n=10)$ & $21.20 \pm 1.39$ & $176.01 \pm 4.63$ & $74.42 \pm 9.11$ \\
Plyometric $(n=10)$ & $21.50 \pm 1.90$ & $176.90 \pm 6.23$ & $71.59 \pm 8.34$ \\
Weight $(n=10)$ & $21.00 \pm 1.05$ & $177.43 \pm 7.37$ & $76.13 \pm 10.54$ \\
\hline
\end{tabular}

$\mathrm{x}$ - mean arithmetic; SD - standard deviation; $\mathrm{n}$ - number of subjects.

Table 2. The statistical analysis of the plyometric and weight groups aerobic-anaerobic power measurements pre and posttest values $(n=10)$.

\begin{tabular}{|c|c|c|c|c|}
\hline Group & Items & Pretest $(x \pm S D)$ & Posttest ( $x \pm S D)$ & $\mathbf{p}$ \\
\hline \multirow[t]{2}{*}{ Bicycle } & Anaerobic Power (kg.m/s) & $116.55 \pm 11.63$ & $122.83 \pm 12.80$ & 0,000 \\
\hline & Aerobic Power (ml.kg/min.) & $356.31 \pm 2.29$ & $385.51 \pm 2.88$ & 0.004 \\
\hline \multirow{2}{*}{ Plyometric } & Anaerobic Power (kg.m/s) & $111,02 \pm 14,88$ & $117,75 \pm 15,53$ & $0,000 *$ \\
\hline & Aerobic Power (ml.kg/min.) & $382,65 \pm 3,04$ & $423,61 \pm 5,43$ & $0,007 *$ \\
\hline \multirow{2}{*}{ Weight } & Anaerobic Power (kg.m/s) & $118,07 \pm 19,55$ & $124,19 \pm 18,86$ & $0,003 *$ \\
\hline & Aerobic Power (ml.kg/min.) & $363,51 \pm 3,85$ & $381,03 \pm 4,11$ & 0,145 \\
\hline
\end{tabular}

$\mathrm{x}$ - mean arithmetic; SD - standard deviation; $\mathrm{p}$ - level of probability; ${ }^{*} \mathrm{p}<0,05$.

Table 3. Comparison of aerobic and anaerobic power pretest-posttest among groups

\begin{tabular}{|c|c|c|c|c|c|}
\hline Groups & & Pretest $(x \pm S D)$ & $\mathbf{p}$ & Posttest (x士SD) & $\mathbf{p}$ \\
\hline \multirow{3}{*}{ Anaerobic Power (kg.m/s) } & BG-PG & $116.54 \pm 11.63$ & 0.438 & $122.82 \pm 12.80$ & 0.482 \\
\hline & BG-WG & $111.02 \pm 14.88$ & 0.830 & $117.74 \pm 15.53$ & 0.849 \\
\hline & PG-WG & $118.07 \pm 19.55$ & 0.324 & $124.19 \pm 18.86$ & 0.373 \\
\hline \multirow{3}{*}{ Aerobic Power (ml.kg/min.) } & BG-PG & $35.63 \pm 2.29$ & 0.071 & $38.55 \pm 2.88$ & 0.056 \\
\hline & BG-WG & $38.26 \pm 3.041$ & 0.611 & $42.36 \pm 5.43$ & 0.816 \\
\hline & PG-WG & $36.35 \pm 3.85$ & 0.183 & $38.10 \pm 4.11$ & $0.034^{*}$ \\
\hline
\end{tabular}

$x$ - mean arithmetic; SD - standard deviation; $p$ - level of probability; ${ }^{*} p<0,05 ; B G$ - Bicycle Group; PG - Plyometric Group; WG - Weight Group. 
group significantly increases the anaerobic power values according to the exercise end result. Another study developed in 2017 concluded that a combined weight training and plyometric training program could represent a more efficient method for improving activities which involve acceleration, deceleration and jumps compared to WT alone [13]. Rodríguez-Rosell [14] reported that only 6 week of preseason low-volume and low-load resistance training combined with plyometrics can lead to relevant improvements in strength, jump, and sprint performance. Hellsten et al. [15] support our work by reporting that bicycle exercise has developed anaerobic power. Six male students performed exercises with $\mathrm{VO}_{2 \max } 90 \%$ in cycling ergonomics for 7 weeks investigated the effects of high intensity endurance exercises on isokinetic muscle strength and at the end of training, they reported a significant increase in $\mathrm{VO}_{2 \max }$ values [16]. Tabata et al. reported that cycling exercises significantly increased the $\mathrm{VO}_{2 \max }$ value by performing them in medium degree of $(70 \%) 60 \mathrm{~min}$ [17]. The results of these studies support our research findings.

Similar to the literature, the anaerobic and anaerobic power values of the pliometer group were significantly increased in favor of the post tests. Study of Sağıroğlu et al. found that there was a significant increase in the anaerobic power values in favor of the group performing pliometer training for 3 days per week in the research in which one group trained for 3 days per week and other group trained 1 day per week In addition, it was determined that the plyometric training performed three days a week was more effective on the anaerobic power and capacity than the plyometric training performed 1 day a week. The reason for this is considered to be the effect of the plyometric training frequency on the development of anaerobic power [18]. Sağıroğlu et al. [19] reported a positive increase in vertical jump performance, which was used to determine anaerobic power of 6-week plyometric exercises in their study in which they used power exercises combined with plyometric exercises performed for 3 days per week throughout 6 weeks. Ateş et al. [20] found that a 10-week plyometric training with football training, has an a positive effect over anaerobic Powers of 16-to 18-year-old footballers. Brown et al. [21] reported that depth jumping exercises performed with 10 men and
10 women significantly increased maximal oxygen use. On the one hand, while the anaerobic power values of the weight exercise group increased significantly in favor of the post test, on the other hand the aerobic power values showed an increase in favor of the post test, there was no statistical significance between the pre test and post test. Adibpour et al. [22] found that power trainings performed by 35 female basketball players for throughout 8 weeks combined with plyometric exercises performed 3 days for a week positively affect the vertical jump performances whih were used to determine anaerobic power. The result of Storen et al. [23] showing that they did not achieve a significant increase in VO2max after maximal strength training for 8 weeks were in parallel with our findings. Hoff et al. [24] reported that maximal strength training with $85 \%$ of maximum 1 repetition performed for 3 times a week for 8 weeks increased aerobic endurance performance. Force training does not reduce $\mathrm{VO}_{2 \max }$, although it normally appears to be a disadvantage in aerobic exercises [9].

While the weighted training with these results produced a significant difference on the anaerobic power, there was no significant increase in favor of the final test, although it increased the aerobic power values.

When the aerobic and anaerobic power pretest and posttest values of the groups were examined in our study, altough there was a significant increase in favour of post test values of plyometric and weight groups $(p<0.05)$, no significant difference was found in all other measurements of the groups $(\mathrm{p}>0.05)$.

\section{Conclusions}

All three groups showed an increase in aerobic power levels, but the increase in cycling and plyometric exercise groups was found to be significant. Similarly, there was a significant increase in anaerobic power in all three groups.

When the values of the plyometric and weight exercises were examined between the groups, it was determined that the increase in the aerobic power value was significantly higher than the bicycle exercise group.

\section{Conflict of interests}

The authors declare that there is no conflict of interests. 


\section{References}

1. Badau D. Investigational approaches of the human physical potential. Publisher by International Science Culture and Sport Association; 2017.

2. Bera SG, Murray DP, Brown LE, Findley BW. Strength Training National Strength and Conditioning Association: Types of Strength and Power Exercises. Human Kinetics; 2007.

3. Badau D, Paraschiv F. Sport games. Theory and methodology. Transilvania University Publishing; 2007. (in Romanian)

4. Badau D, Prebeg G, Mitic D, Badau A. Fitness index and $\mathrm{VO}_{2 \max }$ of physical education students. Ovidius University Annals, Series Physical Education and Sport/Science, Movement and Health. 2015;15(2 S1):246-252.

5. Osipov AY, Kudryavtsev MD, Kramida IE, Iermakov SS, Kuzmin VA, Sidorov LK. Modern methodic of power cardio training in students' physical education. Physical education of students. 2016;20(6):34-39. doi:10.15561/20755279.2016.0604

6. Kim YY, Park SY. Comparison of whole-body vibration exercise and plyometric exercise to improve isokinetic muscular strength, jumping performance and balance of female volleyball players. Journal of Physical Therapy Science. 2016; 28(11):3140-4. doi:10.1589/jpts.28.3140

7. Ateş M, Ateşoğlu U. Effect of plyometric training on upper and lower extremity force parameters of male soccer players aged 16-18 years. Spormeter Physical Education and Sports Science Magazine. 2007; (1):21-28. (in Turkish).

8. Chu DA. Myer GD. Pliometrics, Human Kinetics; 2013.

9. Kraemer WJ, Hatfield DL, Fleck SJ. Strength Training National Strength And Conditioning Association: Types Of Muscle Training. Part 1, Chapter 3, Human Kinetics; 2007.

10.Hamza1d N, Smith R, Davis G. İsokinetic cycling and elliptical stepping: A kinematic and muscle activation analysis. Clin Res Foot Ankle, 2013;1:117. doi:10.4172/2329910x.1000117

11.Karatosun H. Physiological bases of training. 3. Altıntuğ Printing House: Isparta; 2010. (in Turkish)

12.Martinmäki S. Effects of High Intensity Cycling Interval Training on Endurance Performance In Ice-Hockey Players, Master's Thesis Science of Sports Coaching and Fitness Testing; 2012.

13.Rodríguez-Rosell D, Torres-Torrelo J, Franco-Márquez F, González-Suárez JM, González-Badillo JJ. Effects of light-load maximal lifting velocity weight training vs. combined weight training and plyometrics on sprint, vertical jump and strength performance in adult soccer players. J Sci Med Sport. 2017;S1440-2440(17):30241-4. doi:10.1016/j. jsams.2016.11.010
14.Rodríguez-Rosell D, Franco-Márquez F, Pareja-Blanco F, Mora-Custodio R, Yáez-García JM, González-Suárez JM, González-Badillo JJ. Effects of 6 Weeks Resistance Training Combined With Plyometric and Speed Exercises on Physical Performance of Pre-Peak-Height-Velocity Soccer. Players. Int J Sports Physiol Perform. 2016;11(2):240-6. doi:10.1123/ ijspp.2015-0176

15.Hellsten Y, Applev FS, Sjödın B. Effect of sprint cycle training on activities of antioxidant enzymes in human skeletal muscle, Journal of Applied Physiology. 1996;81(4):1484-7.

16. Tabata I, Atomii Y, Kanehısa H, Miyashıta M. Effect of highintensity endurance training on isokinetic muscle power. Eur J Appl Physiol Occup Physiol. 1990;60(4):254-8.

17. Tabata I, Nıshımura K, Kouzak1 M, Hıra1 Y, Ogita F, Miyachı M, Yamamoto K. Effects of moderate-intensity endurance and high-intensity intermittent training on anaerobic capacity and $\mathrm{VO}_{2 \max }$. Med Sci Sports Exerc. 1996;28(10):1327-30.

18.Sağıroğlu İ, Önen ME, Ateș O, Kayatekin M, Șemin İ. Effect of pliometric training on young basketball players on knee extension and flexion isokinetic force values, IU Sports Science Magazine. 2003;11(3):89-93. (in Turkish)

19.Gomez JP, Olmedillas H, Guerra SD, Royo IA, Rodriguez GV, Ortiz RA, Chavarren J, Calbet JA. Effects of weight lifting training combined with plyometric exercises on physical fitness, body composition and knee extension velocity during kicking in football. Appl Physiol Nutr Metabol. 2008;33: 501-10.

20.Ateş M, Demir M, Ateşoğlu U. The effect of plyometric training on some physical and physiological parameters of male soccer players aged 16-18 years. Niğde University Journal of Physical Education and Sport Sciences. 2007;1(1):1-12. (in Turkish)

21.Brown GA, Ray MW, Abbey BM, Shaw I. Oxygen consumption, heart rate, and blood lactate responses to an acute bout of plyometric depth jumps in college-aged men and women. Journal of Strength and Conditioning Research, 2010;24(9):2475-82. doi:10.1519/JSC.0b013e3181b22b63

22.Adibpour N, Bakht HN, Behpour N. Comparison of the effect of plyometric and weight training programs on vertical jumps in female basketball players. World. 2012;7(2):99-104.

23.Storen O, Helgerud J, Stoa EM, Hoff J. Maximal strength training improves running economy in distance runners. Medicine and Science Sports Exercise, 2008;40(6):1087-92. doi:10.1249/MSS.0b013e318168da2f

24.Hoff J, Gran, A, Helgerud J. Maximal strength training improves aerobic endurance performance. Scandinavian Journal of Medicine \& Science in Sports. 2002;12(5):288-95. 


\section{Information about the authors:}

Alpaslan Gorucu; http://orcid.org/0000-0003-0396-7658; alpgorucu@selcuk.edu.tr; Faculty of Sport Sciences, Department of Physical Education and Sport, Selcuk University; Alaeddin Keykubat Yerleşkesi Selçuklu, Karatay-Konya, 42030, Turkey.

Bekir Tokay; http://orcid.org/0000-0003-0059-0736; btokayy@gmail.com; Faculty of Sport Sciences, Department of Physical Education and Sport, Selcuk University; Alaeddin Keykubat Yerleşkesi Selçuklu, Karatay-Konya, 42030, Turkey.

Badau Adela; http://orcid.org/0000-0002-1656-5060; adela.badau@umftgm.ro; Department of Physical Education, Faculty of Medicine, University of Medicine and Pharmacy of Targu Mures; Strada Gheorghe Marinescu 38, Târgu Mureș 540139, Romania.

Cite this article as: Alpaslan Gorucu, Bekır Tokay, Adela Badau. The effects of three different type of exercises on aerobic and anaerobic power. Physical education of students, 2017;21(4):152-157. doi:10.15561/20755279.2017.0401

The electronic version of this article is the complete one and can be found online at: http://www.sportedu.org.ua/index.php/PES/issue/archive

This is an Open Access article distributed under the terms of the Creative Commons Attribution License, which permits unrestricted use, distribution, and reproduction in any medium, provided the original work is properly cited (http://creativecommons.org/licenses/by/4.0/deed.en).

Received: 08.07.2017

Accepted: 25.07.2017; Published: 10.08.2017 